\title{
Efeitos das políticas internacionais e a emergência do PNAIC - PACTO no Brasil
}

\author{
Efectos de las politicas internacionais y la emergencia del PNAIC - PACTO \\ en Brasil
}

The international policies effects and the emergency of the PNAIC-PACT in Brazil

\section{Leandra Bôer Possa ${ }^{1}$}

Universidade Federal de Santa Maria, Docente no Programa de Pós-Graduação em Educação e no Programa de Pós-Graduação em Políticas Públicas e Gestão Educacional, Coordenadora do Grupo de Estudo e Pesquisa em Educação Especial e Inclusão

\section{Patrícia Luciene de Albuquerque Bragamonte ${ }^{2}$}

Universidade Federal de Santa Maria, Programa de Pós-Graduação em Políticas Públicas e Gestão Educacional, Pesquisadora do Grupo de Estudo e Pesquisa em Educação Especial e Inclusão

Resumo: No artigo busca-se mostrar alguns fios que tramam o Pacto Nacional pela Alfabetização na Idade Certa (PNAIC). Não apresentamos nem dizemos uma verdade sobre ele, buscamos identificá-lo como efeito. Metodologicamente este estudo se utiliza da análise do discurso foucaultiano como meio de produzir argumentações a partir do procedimento de apropriação dos enunciados, que são tomados em suas condições de funcionamento, produzindo um sistema para os rituais da palavra e para os planos de apropriação social do discurso. Apresentamos, a partir da análise, uma síntese argumentativa: o PNAIC como um programa-efeito das políticas neoliberais em educação, movimentadas para desenvolvimento econômico e social do neoliberalismo projetado pelos organismos internacionais na educação.

Palavras-chave: Políticas de educação. Organismos internacionais. Pacto Nacional pela Alfabetização na Idade Certa.

Pós-Doutora em Políticas Públicas Educação Comparada pela Universidade de Valencia; Doutora em Educação pela Universidade Federal de Santa Maria.

2 Mestre em Políticas Públicas e Gestão Educacional pela Universidade Federal de Santa Maria; Pós-graduanda em Gestão Pública pela Universidade Federal de Santa Maria. 
Abstract: The intention of this paper is to show some threads that plot of the National Pact for Literacy in the Right Age (PNAIC). It is not in our intention to present or tell the truth about it, but to stress its effects. Methodologically the text consists of an essay of thought that uses the analysis of discourses as a mean of arguing. With the foucaultino appropriation procedure, we analyze the conditions in which discourse occurs in the production of a system, as they appear in the rituals of the word and in the plans of social appropriation of the discourse. The synthesis of argumentation: the PNAIC is a program-effect of neoliberal policies in education, which are the extension of the economic and social development of neoliberalism designed by international organizations in education.

Keywords: Education policies. International organizations. National Pact for Literacy in the Right Age.

Resumen: La intención del texto es mostrar algunas líneas con las cuales se cosen el Pacto Nacional para la Educación en la Edad Cierta (PNAIC). No es nuestra intensión presentar o decir la verdad sobre ello, más entenderlo como efecto. Metodológicamente este ensayo pone en uso el análisis de los discursos foucaultianos para la construcción argumentativa. Con el procedimiento de apropiación hacemos las analices de las condiciones del discurso en la producción de un sistema en los rituales de la palabra y en los planes de apropiación social. La síntesis de la argumentación: el PNAIC es un programa-efecto de las políticas neoliberales en la educación, que son la extensión de lo desarrollo económico y social del neoliberalismo diseñado por organizaciones internacionales en la educación.

Palabras clave: Politicas de educación. Organizaciones internacionales. Pacto Nacional para la Educación en la Edad Cierta.

\section{DAS INQUIETAÇÕES E DAS TRAMAS: UMA INTRODUÇÃO}

A produção da necessidade da alfabetização transformou-a em uma verdade universal, naturalizada e obrigatória. Reivindicamos a alfabetização como direito, buscamos constantemente sua definição, a determinação de critérios certos como idade, método - para sua aquisição, e desenvolvemos os meios para alfabetizar aqueles que, de alguma forma, ainda não estão alfabetizados. De algum modo, no século XXI, tornou-se inquestionável a alfabetização de todos com a ampliação da rede de captura da escola. Cada vez mais cedo as crianças são colocadas na escola 
para serem transformadas em estudantes, o que nos diz que, ao garantir a frequência na escola, é necessário garantir uma escola de qualidade em que todas as crianças sejam alfabetizadas para que possam continuar aprendendo ao longo da vida.

No Brasil, uma produção mais específica sobre a alfabetização das crianças começou nos anos de 1960 (SOARES; MACIEL, 2000). Desde então, as pesquisas foram se intensificando e se rearticulando com outros temas: os estudos sobre a democratização da escola e o fracasso da escola brasileira em alfabetizar a todos; os estudos sobre processos psicológicos (fisiológicos, neurológicos, psicolinguísticos) e pedagógicos (pré-requisitos, métodos, procedimentos, princípios de organização, formação de professores) na aprendizagem; e as investigações em torno dos condicionantes sociais e culturais na alfabetização, a partir de análises sociológicas, antropológicas, econômicas e políticas. Mesmo com distintos enfoques, todas as pesquisas convergem a um lugar comum: aprender a ler e a escrever como "porta" de acesso para uma nova compreensão de mundo.

Imersos nas leituras desses estudos sobre alfabetização, fomos percebendo-a como um desafio para as reformas educacionais. Por um lado, políticas de alfabetização compensatórias para os analfabetos adolescentes, jovens e adultos, por outro lado, políticas capazes de identificar e determinar uma idade certa - uma faixa etária na população -, para ocorrer a alfabetização.

Reformas educacionais em torno da alfabetização se tramam a outros fios, outras políticas e legislações. Isso tem relação com a emergência de uma preocupação legal-jurídica de tornar a criança um sujeito de direito, um sujeito que necessita de proteção integral. Identificamos isso a partir da Constituição Federal (BRASIL, 1988) e do Estatuto de Criança e do Adolescente (BRASIL, 1990). Essa consolidação legaljurídica e também política desencadeará uma série de práticas de cuidados que abarcam desde a primeira infância até a adolescência e pode ser verificada, por exemplo:

a) na área da saúde e assistência social com o acompanhamento da gestação, por meio de ações de saúde e assistência ao pré-natal, com iniciativas de transferência direta de renda - Programa Bolsa Família (PBF), Benefício Variável à Gestante, Benefício Variável Nutri e Benefício de Prestação Continuada da Assistência Social (BPC) - que diminuíram a taxa de mortalidade infantil, como também melhoraram a nutrição da criança pequena; 
b) na área educacional com a transformação da Educação Infantil na primeira etapa da Educação Básica (Lei n. 9394/96), a obrigatoriedade da matrícula aos 6 anos no Ensino Fundamental (Lei n. 11.274/2006) e a ampliação da faixa de escolaridade obrigatória para 4 a 17 anos (Lei n. 12.796/2013).

Com isso, identificamos que essas reformas do sistema público brasileiro - na educação ou na saúde - emergem da necessidade de garantia dos direitos da criança. Em meio a essas reformas, temos acompanhado, em relação à alfabetização, uma "enxurrada" de movimentos envolvendo a sociedade como sócia dos programas educacionais do Governo Federal. De forma direta ou indireta as Organizações não governamentais (ONGs), fundações e institutos, com o foco exclusivo na melhoria do desempenho dos estudantes no processo de alfabetização, têm estabelecido parcerias que, de modo geral, focam a docência em alfabetização, tanto na Educação Infantil quanto nos anos iniciais do Ensino Fundamental. A equação parece ser docentes bem formados igual a estudantes com melhor desempenho e, como resultado da equação, professores estão sendo atravessados constantemente com os discursos de protagonismo, eficiência, novas competências, comprometimento, transformação, mediação, intervenção, diagnóstico, correção, engajamento, responsabilização, entre outros.

Diante disso, temos como intenção neste texto mostrar alguns fios que tramam um dos programas de formação de professores mais "badalados" no Brasil: o Pacto Nacional pela Alfabetização na Idade Certa (PNAIC ou PACTO). ${ }^{3}$ Nossa intenção não é dizer se esse programa é bom ou ruim, mas tentar mostrar como ele se trama com políticas internacionais. Não queremos apresentar ou dizer uma verdade sobre o PNAIC, queremos reconhecê-lo como efeito, ou seja, produzir uma análise que, talvez, nos seja útil para pensarmos sobre aquilo que somos, sobre o que fazem conosco e o que nós fazemos com o que fazem conosco (VEIGA-NETO, 2011a).

\footnotetext{
3 Ao longo do texto poderemos nos referir a esse programa como PNAIC ou como Pacto, pois tanto a sigla PNAIC quanto a palavra Pacto são correntemente utilizadas para se referir ao Pacto Nacional pela Alfabetização na Idade Certa. As ações do Pacto são um conjunto integrado de programas, materiais e referências curriculares e pedagógicas, por meio das quais, o MEC, em parceria com as IES, apoiará os sistemas públicos de ensino dos estados, Distrito Federal e municípios na alfabetização e no letramento dos estudantes até o final do $3^{\circ}$ ano do ensino fundamental, em escolas rurais e urbanas. Essas ações apoiam-se em quatro eixos de atuação: a formação continuada de professores alfabetizadores; os materiais didáticos, literatura e tecnologias educacionais; a avaliação; e a gestão, controle e mobilização social.
} 
Com essa intenção, consideramos importante destacar que as recentes reformulações das políticas educacionais brasileiras, voltadas para a alfabetização das crianças, inserem-se em mobilizações mundiais. Por meio de pactos e alianças com organismos internacionais - Organização das Nações Unidas para a Educação, a Ciência e a Cultura (Unesco), Fundo das Nações Unidas para a Infância (Unicef), Programa das Nações Unidas para o Desenvolvimento (PNUD), Banco Mundial (BM), Organização para a Cooperação e Desenvolvimento Econômico (OCDE), entre outros $-{ }^{4}$ com o setor privado e com as ONGs - como o caso do Todos Pela Educação ,$-{ }^{5}$ o Brasil vem produzindo políticas educacionais que enaltecem a distribuição de responsabilidades e tarefas entre os diferentes contextos de gestão: público, privado e da sociedade civil.

Um exemplo disso é dado por Popkewitz (1998) que, ao analisar reformas educacionais de quatro países - Estados Unidos, Suécia, Rússia e África do Sul -, constatou que o governo das crianças e dos professores se tornou o ponto central dessas reformas. Também identificou a presença constante de organismos internacionais, ONGs e instituições privadas - às vezes mais explicitamente, outras vezes de forma quase invisível -, mas sempre atuantes.

Dessas constatações, podemos considerar que a alfabetização de todas as crianças não é uma especificidade de uma cidade, de um estado ou de um país: é uma preocupação mundial. A alfabetização, na atual conjuntura, em que todos precisam aprender ao longo da vida, é considerada uma etapa essencial da educação.

Metodologicamente, este texto se constitui em um ensaio do pensar. Um texto que se utiliza do discurso sobre a naturalização da necessidade de alfabetizar a todos como um percurso teórico-metodológico para analisar e problematizar o contexto de sua produção. Discursos que, mais que nomear ou posicionar a alfabetização, vêm

\footnotetext{
4 Atualmente há 18 agências, fundos, programas e comissões no Brasil, além de 13 organismos que, apesar de não terem escritório no País, estão presentes por meio de seus programas e projetos (NEVES; PRONKO, 2008).

5 Todos Pela Educação é um movimento fundado em 2006 e de forte expressão, especialmente nas atuais mudanças da legislação brasileira - Plano de Desenvolvimento da Educação (2007), no Plano de Metas Compromisso Todos Pela Educação (2007), no Plano Nacional de Educação, (2014) e no Sistema de Avaliação da Educação Básica (2013). O movimento Todos pela Educação tem como representante máximo o Grupo Gerdau, uma das maiores empresas siderúrgicas em atuação no mercado global. Autodescreve-se como um "movimento da sociedade brasileira que tem como missão engajar o poder público e a sociedade brasileira no compromisso pela efetivação do direito das crianças e jovens a uma Educação Básica de qualidade." Seu objetivo é "ajudar a propiciar as condições de acesso, de alfabetização e de sucesso escolar, a ampliação de recursos investidos na Educação Básica e a melhora da gestão desses recursos." (TODOS PELA EDUCAÇÃO, 2009).
} 
produzindo um modo verdadeiro de se constituir nos sistemas educativos, na formação de professores, nas práticas pedagógicas e, como um modo de normatização da conduta daquele que pode ser considerado alfabetizado, a produção de um sujeito alfabetizado.

Na famosa conferência do Collège de France, em 1970-AOrdem do Discurso -, o foco da discussão de Foucault foram os procedimentos que selecionam, organizam, regulam, controlam e distribuem o que pode ou não ser dito em um determinado tempo e espaço (VEIGA-NETO, 2011b). Como os discursos em si não são nem verdadeiros nem falsos (FOUCAULT, 1996), esses procedimentos - entre as coisas que são ditas - irão fazer essa separação, estabelecendo o que é verdadeiro e o que não é.

Ao apoiarem-se naquilo que Foucault chamou de sistemas de exclusão, eles operam no sentido de interditar, separar e rejeitar e na vontade de verdade da produção dos discursos. Ao tematizar sobre a vontade da verdade, o autor vai dizer que ela é reforçada e reconduzida mais profundamente "pelo modo como o saber é aplicado numa sociedade, como é valorizado, distribuído, repartido e, de certo modo, atribuído" (FOUCAULT, 1996, p. 17) e, por efeito, produz um processo de naturalização onde "só aparece aos nossos olhos uma verdade que seria riqueza, fecundidade, força doce e insidiosamente universal. E ignoramos [...] como prodigiosa maquinaria destinada a excluir." (FOUCAULT, 1996, p. 20).

A partir desses entendimentos, o que se busca, portanto, é mostrar - a partir da análise do Caderno de Apresentação do Pacto Nacional de Alfabetização na Idade Certa - a relação de conceitos por um procedimento de apropriação (FOUCAULT, 1996), buscando verificar a relação destes com outros conceitos e/ou princípios sobre a alfabetização, registrados em documentos internacionais, que vão possibilitar as condições de funcionamento para que a alfabetização se torne tema central nas políticas educacionais, como um sistema que passa a ser representado pela palavra nos contextos de apropriação social do discurso.

Em um primeiro momento do ensaio, identificamos a superficialidade (no sentido de sua caraterística rizomática) da palavra e do discurso sobre alfabetização, bem como os efeitos esperados desse discurso, pois o que nos interessa são os "contatos de superfície que ele mantém com aquilo que o cerca" (VEIGA-NETO, 2001, p. 57); e, no segundo momento, a apropriação social do discurso, os saberes e os poderes que ele traz consigo (FOUCAULT, 1996) - quando este passa a ser elemento central da formação de professores a partir do Pacto. 
Para isso, elegemos como material de análise documentos (declarações, textos, esquemas que registram discursos das organizações internacionais e nacionais) com o poder de ordenar, em um tempo histórico, um modo de dizer e fazer a verdade em educação; e documentos onde estão registrados enunciados que consideramos importantes para identificar o contexto mais amplo de governamentalidade do PNAIC. A eleição dos materiais ocorreu pelo vasculhamento aleatório de diferentes documentos editados onde podíamos identificar a educação e a alfabetização em situação de governamentalidade, ou seja, onde apareciam como governamento ${ }^{6}$ da população - a partir do uso da tecnologia política da estatística - e como determinante do desenvolvimento econômico.

Alfabetização na infância; alfabetização como condição inquestionável da habilidade humana de viver na contemporaneidade; infância como um conjunto de saberes para estabelecer condução da conduta infantil até a maioridade; alfabetização narrada como etapa educacional primordial do desenvolvimento do indivíduo; como etapa de preparação para aprendizagem ao longo da vida. Estes enunciados que se constituem em fator político, em referência para elaborar, desenvolver e monitorar (avaliar) políticas públicas de educação para um grupo populacional. Alfabetização na idade certa como um indicador do desenvolvimento econômico, uma necessidade que potencializa o desenvolvimento de habilidades individuais que podem ser quantificadas e qualificadas como meio de ascensão a outros tipos de bens como o mercado laboral, a produtividade laboral econômica, bem como bens psicossociais como satisfação pessoal e participação cidadã.

Diante disso, vale confessar, metodologicamente, que gostamos dos discursos, não porque eles dizem alguma verdade, mas porque eles a inventam. Mas, além de gostar dos discursos, queremos mostrá-los em atuação, como práticas. O que nos parece é que somos atraídos pelos perigos dos discursos, buscando neles entender os modos de vida projetados fora e dentro de nós mesmos, porque trabalhar com a análise dos discursos, nessa perspectiva, não tem a função de classificá-los como bons ou ruis, certos ou errados, mas entendê-los como perigosos, como sempre tendo algo para fazer com eles (FOUCAULT, 1999).

\footnotetext{
6 Neste texto, o uso da palavra governamento tem a mesma função da palavra governança que, seguindo a proposta de Veiga-Neto (2002), faz referência à ação ou ato de governar(-se), como ato que se exerce sobre uma pessoa ou que ela exerce sobre si mesma para controlar suas ações.
} 
Por isso, assumimos aqui a tentativa de análise do discurso sabendo que "o método não é o caminho seguro [...] até porque nada mais é seguro, previsível: nem os pontos de saída, nem o percurso, nem os pontos de chegada" (VEIGA-NETO, 1996, p. 184), mas que o método, como uma caixa de ferramentas, oferece instrumentos que orientam uma análise e fazem da crítica um martelo, ${ }^{7}$ permitindo ver algumas tramas que engendram os discursos sobre políticas educacionais de alfabetização de crianças no Brasil.

Apresentamos, então, com base na análise de documentos, uma síntese argumentativa que busca mostrar e compreender o PNAIC como um programaefeito das políticas neoliberais em educação, que tem movimentado a perspectiva de desenvolvimento econômico e social dado pelos organismos internacionais para a alfabetização de crianças no Brasil.

\section{2 “ORIENTAÇÕES” INTERNACIONAIS E EFEITOS: O PNAIC- PACTO}

O que significa pactuar quando nos referimos a pensar sobre o PNAIC - PACTO? A partir de conversas trocadas por e-mail com as autoras, Veiga-Neto, interessado em investigar como um programa de alfabetização é nomeado com esse nome, nos ajuda a pensar etimologicamente na palavra "pacto". O referido autor traz uma etimologia interessante: do latim pactum, pacti, que significa ajuste, convenção, ligação entre diferentes. Em uma raiz indo-europeia é pak, fixar, atar, juntar, ligar. Para ele, várias palavras pertencem ao mesmo campo semântico: paz (vínculo, acordo entre pessoas); pauta (conjunto de regras para governar); compacto e impacto; pago (distrito agrícola onde as pessoas se juntavam); pagão (aqueles que, na Alta Idade Média, viviam no campo ou pago e resistiam à vida nas cidades, onde se começava a praticar o cristianismo); país (território rural); paisagem (imagem rural); paisano (habitante rural); poste e palanque (fixado em terra); trabalhar, pelo latim vulgar tripalio (tri + palio), o cepo em forma triangular, feito com três tábuas cruzadas, no qual se amarravam os réus para torturá-los (o trabalho era associado à tortura).

\footnotetext{
7 A Filosofia do Martelo pode ser mais bem entendida a partir de Nietzsche no livro Crepúsculo dos Ídolos (NIETZSCHE, 1988).
} 
A ajuda e o alerta de Veiga-Neto em relação às diversas semelhanças etimológicas da palavra "pacto" com outras como: acordo, cooperação, práticas coletivas, territórios, fixação, trabalho e tortura e, mais especificamente, seu alerta sobre a relação dela com uma gramática neoliberal, nos remete a compreender a governamentalidade neoliberal que tem como princípio a globalização econômica e do mercado, mas também um modelo de relações sociais e culturais. Como aponta Saura (2016, p. 15):

Estas formas de gobierno neoliberal o «conducción de las
conductas» son los nuevos modos de gubernamentalidad del
gobierno de las almas (Foucault, 1991) que van confeccio-
nándose desde mediados del siglo XX. La visión de análisis del
neoliberalismo como gubernamentalidad o mentalidad de go-
bierno centra el foco de atención en las formas de ejercer una
gubernamentalización de Estado (Lemke, 2001) o guberna-
mentalización de lo social (Dean, 1999). Para ello se requieren
tecnologías políticas y «racionalidades de gobierno» mediante
una gubernamentalidad activa (Foucault, 2007: 154) que go-
bierna para el mercado y se erige para producir la competen-
cia. Las tecnologías politicas coexisten con diversas racionali-
dades politicas donde el «modo de conducta se rige a través de
la libertad», en relaciones interconectadas entre "gobierno, los
autos-gobernados y el espacio de administración» (Ong, 2007:
4). La gubernamentalidad neoliberal se sostiene como politicas
de Estado que se fundamentan en dirigir la conducta de las
conductas a través de estrategias de libertad que responsabili-
zan a los sujetos de sus aciertos y errores. (BURCHELL; GOR-
DON; MILLER, 1991; DEAN, 1999; ROSE; MILLER, 1992).

Pactuar nesse contexto e, aqui ainda de forma aligeirada, pois estamos a pensar sobre isso em outro trabalho, tem se constituído em um tipo de protocolo contemporâneo de governança dos Estados, das instituições (públicas e privadas) e da população, que como direção de conduta atinge a todos e a cada um. Isso podemos identificar em alguns fragmentos nos documentos vasculhados, quando esses disseminam princípios que mobilizam a inclusão de todos na tomada de decisões sobre a educação, e quando responsabilizam a todos pelos processos educativos.

O movimento Todos Pela Educação faz um chamamento para um pacto entre a sociedade, os gestores públicos e privados e, de uma forma especial, para que eu e você realizemos um esforço de nação republicana: fazer com que a Educação seja assumida como urgência - portanto, muito mais do que uma prioridade -, sem a qual nosso País não terá futuro. (TODOS PELA EDUCAÇÃO, 2009, p. 23). 
Diante do diagnóstico apontado pelos resultados da Prova Brasil, da Provinha Brasil e do PISA, que identificaram os desafios na alfabetização das crianças até os oito anos de idade, e em atendimento à Portaria $n^{\circ} 867$, de 4 de julho de 2012, este Ministério implementou o Pacto Nacional pela Alfabetização na Idade Certa em parceria com Estados e Municípios e Distrito Federal. (BRASIL, 2015a, p. 19).

[...] trabalho coletivo na escola, incluindo a inserção da/na comunidade em que a escola está inserida, exige momentos especialmente dedicados aos encontros entre professores, equipe pedagógica, pais de alunos e membros da comunidade. (BRASIL, 2015a, p. 21).

[...] desenvolvimento de parcerias, redes e alianças de valor estratégico para o fortalecimento das Secretarias Municipais de Educação. (UNDIME, 2012, p. 120).

Sob a perspectiva do monitoramento estatístico do desempenho e resultados, como aponta o segundo fragmento, até nos sinônimos (outros fragmentos) utilizados para a palavra "pacto" - rede e aliança - vemos os efeitos da governança neoliberal na educação. Governança que se constitui em uma doutrina transformada em política educacional, que aparece como tecnologia de governo e de neoliberalização dos setores públicos de educação e de suas instituições (BALL, 2014). Trabalhar juntos para produzir novas práticas, subjetividades e oportunidades se constitui em um efeito produzido pela tática de que todos devem prestar contas (avaliação em larga escala) e, com isso, se possa identificar e qualificar os produtos que os sistemas e as instituições estão a produzir, ou seja, qual capital humano estão a produzir.

Nesse sentido, pactuar a educação é inseri-la na ordem dos negócios em que se pode medir satisfação dos clientes via investidores das melhores práticas, das mais eficientes e eficazes, que - como diz em outro documento da ODCE - permita " $\mathrm{el}$ control de calidad general en el sistema educativo, y [...] el desarrollo y supervisión de programas y politicas especificos dirigidos a las mejoras escolares" (OCDE, 2011, p. 161), porque:

El interés actual en el desempeño escolar en muchos países gira en torno a temas sobre la eficacia de inversiones en las escuelas, junto con la preocupación extendida sobre la competitividad económica nacional. Dado el papel central del capital humano en la economía moderna (Friedman, 2005; OCDE, 1994, 1996, 2001, 2010), las escuelas de una nación se ven como fuente potencial de ventaja competitiva. (OCDE, 2011, p. 20). 
Uma vantagem competitiva que está sendo nomeada a partir de três elementos integrados: os "procesos de mejora escolar, la rendición de cuentas de las escuelas y la posibilidad de elección de escuela." (OCDE, 2011, p. 20). Isso nos leva a identificar que a dimensão curricular e pedagógica dos processos de ensino e de aprendizagem é o resultado de um tipo de reforma geral do sistema educacional, de suas políticas, legislação, financiamento, uma dimensão que passa a ser entendida como prestação de serviços, mais um produto a ser consumido como bom produto, como boa prática, entre a boa governança do sistema.

Tornar a educação de todos e de cada um, porque trabalhar por e para educação é, também, tornar todos e cada um juízes da prestação de contas da escola pública e de sua melhoria ou não. Isso significa investir em mobilização social, recursos humanos, novos instrumentos técnicos, sistemas de informação, administração participativa e fortalecimento de parcerias entre agentes públicos, privados e atores sociais. Com isso, produzir a sensação do acesso sem restrições, propagar a igualdade de oportunidades para que todos e cada um se sintam estimulados a aproveitar a oportunidade, a participar, a investir e autoinvestir para o aumento do capital humano, pelo desenvolvimento de habilidades e competências que estão colocadas a serviço da inovação, de novos saberes e aprendizagens; uma preparação para aprendizagens ao longo da vida, o que, de alguma forma, recompensaria tanto o Estado pelo investimento em educação quanto qualquer outro investidor.

Essa governança, entendida a partir da noção de governamentalidade, ${ }^{8}$ indica um governo sobre todos, um governo sobre cada um e um governo sobre si mesmo, como afirma Foucault (2008), uma lógica de empreendedorismo via pactos (redes e alianças) que se projeta para a programação calculada de reformas educacionais de forma mais ampla e para uma programação de estratégias ${ }^{9}$ para que a atividade dos indivíduos e seus modos de agir se constituam em capital humano.

Nessa perspectiva, o PNAIC - Pacto - no Brasil vem pactuar com o desenvolvimento do capital humano na medida em que investe em uma formação

\footnotetext{
8 "Conjunto constituído pelas instituições, procedimentos, análises e reflexões, cálculos e táticas que permitem exercer essa forma bem específica, bem complexa de poder, que tem como alvo principal a população, como forma mais importante de saber, a economia política como instrumento técnico essencial, os dispositivos de segurança." (FOUCAULT, 2012, p. 303).

9 "Somos a-sujeitados por redes contínuas de vigilância e controle, subjetivando-nos a encontrar, nos espaços formativos e de atuação, meios para constituir em si e para si competências e habilidades para que possamos ser reconhecidos, adequados, produtores, consumidores e, principalmente, politicamente corretos em relação aos outros e em relação à nossa atuação." (POSSA; NAUJORKS, 2014, p. 326).
} 
continuada de professores pautada no direito à aprendizagem, que se dá a partir de determinadas características específicas - para garantir esse direito há que se delimitar o que aprender e como aprender para que se possa averiguar e monitorar se esse direito está sendo garantido - e pela inclusão - pois só será possível o investimento no capital humano (na aprendizagem) de todos que estiverem dentro dessas práticas. Por isso, o programa busca o engajamento de todos e de cada um na aprendizagem que delineia um processo potente de individualização dos indivíduos, aumentando o controle sobre cada sujeito, uns sobre os outros e sobre si:

Com certeza foi um momento de grande aprendizado para todos os participantes: gestores, coordenadores, supervisores, orientadores e professores. Dada a dimensão do programa e a universalidade de seu alcance, os aprendizados foram distribuídos pelas instâncias pedagógicas, administrativas e técnicas, mobilizando variada gama de saberes. [...] para além da socialização, trata-se de um elemento fundamental no processo de formação [...] através da colaboração, busca-se a formação de uma rede [...] (BRASIL, 2015a, p. 28).

No caso do PNAIC, a partir dos direitos de aprendizagem [...] cada professor tem autonomia e liberdade [...] Cada docente tem liberdade e autonomia para selecionar os instrumentos de diagnóstico e avaliação, tanto para acompanhar a apropriação do SEA, como para diagnosticar os avanços no âmbito do letramento [...] o PNAIC vê o professor como um especialista, com saberes próprios de sua profissão, o ensinar, e porque concebe o ensino como uma atividade que só pode ser inclusiva e respeitosa se o sujeito que a conduz tem uma intencionalidade em seus gestos e tomadas de decisão. (BRASIL, 2015b, p. 63).

Entendemos que o que o PNAIC propõe é que não se pode avançar na democratização da alfabetização plena, para todos os cidadãos, sem assumir um norte: os direitos de aprendizagem dos educandos. Tampouco avançaríamos, se não lutássemos para assegurar uma perspectiva inclusiva, em que os professores buscarão, sempre, ajustar o ensino a todos os seus alunos que precisam ser ajudados, sejam pessoas com deficiência ou apenas crianças que ainda não construíram certos conhecimentos de que a maioria da turma já se apropriou. (BRASIL, 2015b, p. 65).

Esse pacto em torno de um processo de alfabetização de todos está caracterizado fortemente no discurso das políticas globais de investimento na equidade e na qualidade, e no compromisso dos governos de garantia de uma educação que satisfaça as necessidades básicas de aprendizagem de todas as crianças, jovens e adultos, especialmente a partir da Declaração Mundial sobre a Educação 
para Todos (1990) e a Declaração de Dakar - Educação para Todos (2001). Com uma grande ênfase no direito à aprendizagem, vários movimentos são elaborados para a instauração de uma política nacional de alfabetização de todas as crianças. Todos estes movimentos tomam como referência os índices das avaliações de larga escala que aparecem, no Brasil, com criação do Sistema Avaliação da Educação Básica ${ }^{10}$ (SAEB) no ano 1990 e, consequentemente, com o refinamento ${ }^{11}$ do sistema, os modelos específicos de avaliação produzem práticas de responsabilização do professor por meio dos resultados de rendimento da aprendizagem dos estudantes cada vez mais individualizados.

A preocupação em monitorar constante e estatisticamente a população infantil e seus processos de alfabetização, a nível local e global, é um dos objetivos de diferentes organismos internacionais. A ONU, por meio da Unesco como agência especializada, e da Unicef como união de programas e fundos, desde a década de 1970 (entre 1976 e 1989) ocupou um papel importante para dizer em dimensão global da necessidade de todos os países se preocuparem com o processo de preparação (de aprendizagem ao longo da vida) de todos os indivíduos (WERTHEIN; CUNHA, 2010, 2000). Um alerta, ainda mais específico, coloca como desafio o enfrentamento dos problemas de acesso e qualificação dos processos de ensino e aprendizagem no que se refere a políticas que possam preparar as novas gerações.

10 De 1990 até 1995 o Sistema chamava-se Sistema Nacional de Avaliação do Ensino Público (SAEP) de $1^{\circ}$ grau.

11 Ainda na década de 1990 importantes reformulações do Sistema de Avaliação da Educação Básica foram garantindo uma precisão maior nos resultados das avaliações em larga escala, como: a introdução da metodologia da Teoria da Reposta ao Item (1995); a inclusão do Ensino Médio (1997); e a criação da Escala de Desempenho que compara os diferentes anos avaliados por meio da relação proficiência $\mathrm{x}$ habilidade (1997). Em 2005, com a instituição da Rede Nacional de Avaliação, o sistema passa a ser composto por dois distintos, porém complementares, processos de avaliação: a Avaliação Nacional da Educação Básica (ANEB), que consiste em uma avaliação em que os alunos e as escolas, públicas e privadas, são amostrados; e a Avaliação Nacional do Rendimento Escolar (Anresc), que é criada com o objetivo de avaliar o ensino ministrado em todas as escolas públicas urbanas do território nacional, sendo uma avaliação censitária e obrigatória. Em 2007 e 2009 temos a inclusão das escolas rurais na Anresc. Em 2008 a Provinha Brasil foi aplicada pela primeira vez, sendo uma avaliação censitária, mas não obrigatória. A partir de 2013 tivemos a inclusão da Avaliação Nacional da Alfabetização (ANA) prevista no Pacto Nacional pela Alfabetização na Idade Certa (PNAIC), destinada aos alunos do $3^{\circ}$ ano do Ensino Fundamental. A ANA permite que se avalie o sistema escolar para pautar a definição de políticas públicas que busquem a melhoria da alfabetização. Neste processo, a criação do Índice de Desenvolvimento da Educação Básica (IDEB), em 2007, reúne, em um só indicador, os resultados de dois conceitos igualmente importantes para a qualidade da educação: o fluxo escolar e as médias de desempenho nas avaliações. É uma ferramenta que acompanha as metas de qualidade para a educação básica, que tem estabelecida, como meta principal, alcançar a média 6,0, que corresponde a um sistema educacional de qualidade comparável ao dos países desenvolvidos participantes da OCDE. 
A infância e a criança, como foco de preocupação e de estabelecimento de políticas específicas, geram uma atenção especial considerando a formação e preparo delas nas primeiras etapas de escolarização: a educação infantil e os processos de alfabetização. Essa preocupação está expressa na Declaração Mundial de Educação para Todos de 1990, quando em seu preâmbulo expressa a realidade a ser modificada:

mais de 100 milhões de crianças, das quais pelo menos $60 \mathrm{mi}-$ lhões são meninas, não têm acesso ao ensino primário; [...] mais de 100 milhões de crianças [...] não conseguem concluir o ciclo básico, e outros milhões, apesar de concluí-lo, não conseguem adquirir conhecimentos e habilidades essenciais. (UNESCO, 1990, p. 2).

Essa Declaração Mundial, além de estabelecer metas a serem consolidadas e ratificadas por todos os Estados-Nações, identifica a educação básica como "a base para a aprendizagem e o desenvolvimento humano permanentes, sobre a qual os países podem construir, sistematicamente, níveis e tipos mais adiantados de educação e capacitação.” (UNESCO, 1990, p. 3). Ainda define, como podemos ver na própria Declaração, quais serão as necessidades individuais de educação para todos, o que sugere as características das necessidades de cada um e de todos: "Cada pessoa criança, jovem ou adulto - deve estar em condições de aproveitar as oportunidades educativas voltadas para satisfazer suas necessidades básicas de aprendizagem." (UNESCO, 1990, p. 3, grifo nosso).

Ao definir as necessidades de todos e de cada um, diz quais seriam elas:

Essas necessidades compreendem tanto os instrumentos essenciais para a aprendizagem (como a leitura e a escrita, a expressão oral, o cálculo, a solução de problemas), quanto os conteúdos básicos da aprendizagem (como conhecimentos, habilidades, valores e atitudes), necessários para que os seres humanos possam sobreviver, desenvolver plenamente suas potencialidades, viver e trabalhar com dignidade, participar plenamente do desenvolvimento, melhorar a qualidade de vida, tomar decisões fundamentadas e continuar aprendendo. (UNESCO, 1990, p. 3, grifo nosso).

Essa preocupação com a aquisição de competências no período de alfabetização gera a necessidade de monitoramento do analfabetismo, dos níveis, resultados e qualidade dos processos de alfabetização. Isso é expresso nos dados numéricos da população, que passam a ocupar um espaço relevante entre os indicadores de desenvolvimento social. 
No modelo de monitoramento da alfabetização, a partir de indicador de desenvolvimento social, outra organização internacional tem exercido um importante papel a partir dos anos 2000. A Organização para a Cooperação e Desenvolvimento Econômico (OCDE) vem produzindo indicadores cada vez mais difundidos para que todos os países possam se utilizar de um modelo de avaliação de larga escala, o Programa Internacional de Avaliação de Alunos (PISA) - da OCDE - que globalmente vem produzindo medidas e comparações de séries estatísticas históricas de indicadores educativos, dos níveis e rendimentos educacionais da população e, com isso, avaliando os sistemas educativos no mundo.

O monitoramento dessas organizações internacionais, como a OCDE e o Instituto de Estatística da Unesco, tem mobilizado no Brasil uma importante prática de pesquisa estatística e formulação de indicadores espelhados em práticas consolidadas globalmente. Em específico, para os processos de escolarização, no nível da alfabetização, além de dados gerais da população e de suas características econômicas, sociais, laborais, habitacionais, vêm se especializando os indicadores para o desenvolvimento de medidas e índices quantitativos sobre a população em idade escolar, seu acesso e processo de escolarização, bem como de alfabetização. ${ }^{12}$

Por outro lado, o Brasil tem fornecido os números para que a OCDE monitore o financiamento, possa avaliar o nível de investimento e de gastos em educação, bem como os resultados destes. Oferece os dados para que a OCDE observe, por meio de indicadores, o rendimento dos estudantes com a aplicação da avaliação de larga escala elaborada pelo PISA e, ainda, o nível de formação dos professores e seus salários, o modelo de gestão do sistema educativo brasileiro, que pode ser comparado com qualquer outro país.

No Brasil, as políticas de avaliação têm se ocupado de seguir o exemplo da OCDE nas avaliações de larga escala, pois o

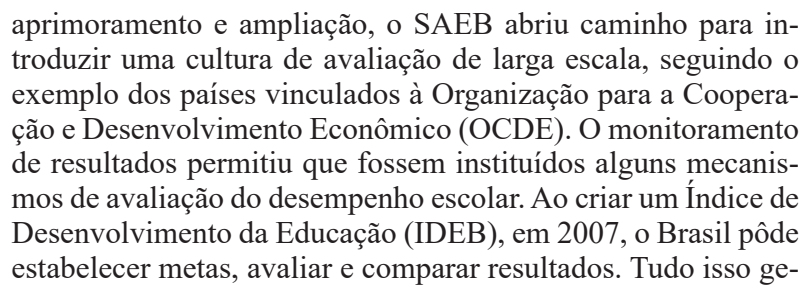

12 Para mais informações ver nota 9. 
rou forte impacto sobre os indicadores de resultados. (BRASIL, 2014, p. 17).

Em relação aos efeitos das determinações dos organismos internacionais. de modo mais efetivo nas reformas educativas, podemos identificar a década de $1990^{13}$ como um indício para a consolidação das práticas de testes, inquéritos e avaliações estatísticas de larga escala, sendo esses espelhados em modelos e indicadores oferecidos pelos organismos internacionais:

Esse tipo de avaliação ganhou relevo no país nos anos 90, tendo predominado [...] o esclarecimento das características e finalidades dos sistemas de avaliação e busca as justificativas para adotá-los. Esse discurso servirá, de certo modo, como substrato à fala oficial. Vários dos textos arrolados constituíram apresentações feitas em seminários promovidos por órgãos de governo, como o Encontro sobre Qualidade da Educação, realizado por iniciativa da Coordenação de Planejamento Setorial do MEC, da Secretaria de Ciência e Tecnologia do Paraná e da Oficina Regional de Educação para a América Latina e o Caribe Orealc/ Unesco , em Brasília, em 1990, e o Seminário Nacional sobre Medidas Educacionais, realizado pelo MEC/Inep e Programa das Nações Unidas para o Desenvolvimento PNUD, em 1992. Ambos visavam oferecer subsídios ao desenvolvimento de ações relacionadas ao delineamento e implementação de sistemas de avaliação da educação básica no país. (BARRETO et al., 2001, p. 65).

Parece-nos que existe uma coincidência entre novas e outras práticas de avaliação educacional em larga escala e a Declaração Mundial de Educação para

\footnotetext{
13 Barreto et al. (2001) vasculham trabalhos científicos em torno do tema avaliação do sistema educacional no Brasil (avaliação da escola, dos alunos e das políticas e programas) e nos oferecem, com essa amostra e análise dos trabalhos, a década de 1990 como uma estimativa sobre um movimento mais sistemático de monitoramento, via avaliação de desemprenho ou de análise de resultados dos investimentos, dirigidos às políticas, programas e ações em educação. Apontam, ainda, que a avaliação em larga escala começa no início dos anos 1990 e que durante essa década se expandiu, tendo como foco a "avaliação de sistema, entendida como avaliação externa e padronizada do rendimento dos alunos das redes escolares." (BARRETO et al., 2001, p. 57). Apontam as autoras que os modelos de avaliação de larga escala no Brasil tomavam, à "guisa de ilustração [...] modelos adotados nos Estados Unidos: o de avaliação de insumos, o de processo de ensino-aprendizagem e o de rendimento escola." (BARRETO et al., 2001, p. 58). Os autores já apontam, a partir dos estudos analisados, o perigo que esses processos de avaliação engendram, estando "associado à ideia da accountability, ou seja, de que a produção e divulgação de informações sobre os conhecimentos que os alunos adquirem na escola." (BARRETO et al., 2001, p. 59) e a crescente relação disso com as formas e usos dos resultados no sentido de desgastar os serviços públicos de educação para reavivar o princípio da liberdade de mercado e consumo no âmbito educacional. Um perigo hoje confirmado nos estudos de Ball (2014).
} 
Todos (UNESCO, 1990). ${ }^{14} \mathrm{Na}$ Declaração, no art. $4^{\circ}$, encontramos o indício para a ampliação desse tipo de avaliação com foco nos resultados de aprendizagem:

[...] a educação básica deve estar centrada na aquisição e nos resultados efetivos da aprendizagem, e não mais exclusivamente na matrícula, frequência aos programas estabelecidos e preenchimento dos requisitos para a obtenção do diploma [...]. Daí a necessidade de definir, nos programas educacionais, os níveis desejáveis de aquisição de conhecimentos e implementar sistemas de avaliação de desempenho. (UNESCO, 1990, p. 4).

\section{Ao fim e ao cabo, a Declaração de Educação para Todos, que tinha em seu bojo} uma proposta de educação de visão ampliada, como aponta Botega (2005), encontrou um equivalente para gerenciar um modelo de educação global que se sistematizou no termo Educação Básica. ${ }^{15} \mathrm{Na}$ análise de alguns autores brasileiros (FRIGOTTO; CIAVATTA, 2003; GADOTI, 2000; LIBÂNEO, 2012), o impacto desse equivalente se constituiu em um enxugamento/encolhimento das políticas educacionais por parte do Estado, que resultou nos anos 1990 no cumprimento da expansão e avaliação de resultados sobre a escolaridade primária, ou seja, a alfabetização. ${ }^{16}$

\footnotetext{
14 Vale ressaltar o jogo de interesses que configurou as condições de produção dessa Declaração: para a Unesco foi a diversidade, as minorias e a preocupação com o analfabetismo (principalmente da população feminina), tendo papel importante para a invenção de uma nova categoria "no discurso pedagógico: a equidade. Até 90, falava-se muito na igualdade de oportunidades. A partir daí, passa-se a trabalhar com a categoria de equidade. O contrário de igualdade é desigualdade e de equidade é iniquidade." (GADOTTI, 2000, p. 28). "O Unicef enfatizou a educação integral e suas necessidades básicas. O novo enfoque da Conferência de Jomtien passou a ser a educação não mais identificada como escolaridade [...] a Unicef tentou dar uma conotação mais qualitativa, abordando qualidade de vida, de nutrição e de saúde das crianças. O Programa das Nações Unidas para o Desenvolvimento (PNUD) realçou a ideia de que a melhoria dos índices de educação acabaria produzindo melhor crescimento econômico. O Banco Mundial esteve mais preocupado com o gerenciamento dos recursos, batendo na tecla de que há recursos para a educação, mas são mal aproveitados." (GADOTTI, 2000, p. 28-29).

15 "Educação básica foi, então, um termo de consenso no qual se mesclaram as visões, prioridades e agendas de cada um dos sócios internacionais, de Jomtien, dos países e dos inúmeros especialistas nacionais e internacionais por cujas mãos passaram as sucessivas versões dos documentos. Como tal, é um termo atravessado por incoerências e contradições, segundo revelam os próprios documentos de Jomtien e aqueles produzidos posteriormente pelas diversas agências sobre a Educação para Todos. Um termo que já tinha vida e usos próprios (e diversos) nos diferentes países antes de Jomtien e ao qual, como vimos, não era fácil atribuir um novo significado somente acrescentando a ele o nome de visão ampliada." (TORRES, 2001, p. $15)$.

${ }_{16}$ "A uniformização da política educativa em escala global está vinculada ao crescente peso dos organismos internacionais no projeto e na execução da política educativa nos países em desenvolvimento" (TORRES, 2001, 79). "Este crescimento está, sobretudo, associado ao fato de em especial de o Banco Mundial, o sócio mais forte da Educação para Todos, ter atingido a condição de uma liderança no cenário educativo dos anos 90. Esta condição foi assumida a partir do momento em que o BIRD começa a impor, através da proposta de um programa de reformas estruturais neoliberais, condicionantes aos países que recorrem aos seus financiamentos, um forte pacote de reforma educativa, principalmente na educação primária [...] Prioridade depositada sobre a educação básica, entendida como educação primária; Melhoria da qualidade
} 
Podemos identificar nessa Declaração cinco fios condutores e um tipo de racionalidade que mobiliza as reformas e políticas educacionais como meta global, são eles:

a) a universalização do acesso à educação básica para todos e de forma equânime, concentrando-se no investimento, avaliação e monitoramento de desempenho dos processos de aprendizagem e, por isso, a importância de fixar padrões de aprendizagem essenciais como necessidades educacionais de todos e de cada um para poderem ser medidas, avaliadas e comparadas em larga escala;

b) políticas de financiamento da educação fixando e flexibilizando insumos que, a partir de indicadores, tenham efeito no rendimento escolar. Para um destes, os professores, sua carreira e formação, passando a ser avaliadas a eficiência e a competência pedagógica, bem como incrementando a formação continuada para que se responsabilizem pelos resultados;

c) ampliação dos raios da educação básica, o que imprimiu nas legislações e políticas educacionais a ampliação do tempo de escolaridade obrigatória em anos, bem como para em tempo cotidiano, com discussões sobre educação integral, tendo esta uma função de gerenciamento do risco para grupos específicos que são declarados como

[...] os pobres: os meninos e meninas de rua ou trabalhadores; as populações das periferias urbanas e zonas rurais os nômades e os trabalhadores migrantes; os povos indígenas; as minorias étnicas, raciais e linguísticas: os refugiados; os deslocados pela guerra; e os povos submetidos a um regime de ocupação. (UNESCO, 1990, p. 4).

(e da eficácia) da educação como eixo da reforma educativa. A qualidade da educação localiza-se nos resultados e esses se verificam no rendimento escolar. Os fatores determinantes de um aprendizado efetivo são, em ordem de prioridade: bibliotecas, tempo de instrução, tarefas de casa, livros didáticos, conhecimentos e experiência do professor, laboratórios, salários do professor, tamanho da classe. Levando-se em conta os custos e benefícios desses investimentos, o BIRD recomenda investir prioritariamente no aumento do tempo de instrução, na oferta de livros didáticos (os quais são vistos como expressão operativa do currículo e cuja produção e distribuição deve ser deixada ao setor privado) e no melhoramento do conhecimento dos professores (privilegiando a formação em serviço em detrimento da formação inicial)." (BOTEGA, 2005). 
d) gestão de ambientes de aprendizagem que sejam a escola como instituição, mas ampliando para uma sociedade de aprendizagem que coloque: "Todos os instrumentos disponíveis [...] na transmissão de conhecimentos essenciais, bem como na informação e educação dos indivíduos quanto a questões sociais." (UNESCO, 1990, p. 5). Esses instrumentos caracterizados como tradicionais e os canais de informação, comunicação e ação social. Esses instrumentos, "as bibliotecas, a televisão, o rádio e outros meios de comunicação de massa podem ser mobilizados em todo o seu potencial, a fim de satisfazer as necessidades de educação básica para todos”. (UNESCO,1990, p. 05). Colocar o espaço da sociedade como um todo, envolvida no sentido do empreendimento educacional e cada um em todo o seu tempo e ao longo da vida conectado com a possibilidade de educar-se;

e) investimento e o fortalecimento de alianças (os pactos que apontamos no início desta sessão) com a convocação de toda a sociedade para conhecer e participar dos assuntos educacionais, mas, mais que isso, para serem corresponsáveis. A perspectiva de "Fortalecer as alianças" (UNESCO, 1990, p. 5) implica reconhecer o papel especial dos professores, administradores e do pessoal que trabalha em educação, como, também, estabelecer alianças com organizações governamentais e não governamentais, com o setor privado, com as comunidades locais, com grupos religiosos e com as famílias. Nesse sentido, a intervenção cada vez mais frequente dos organismos internacionais na educação, bem como as instituições não governamentais e privadas que lhes respaldam, se constitui em um terreno fértil para germinar movimentos que acreditam que as ações governamentais não são suficientes para que o País atinja a qualidade educacional, pressionam os Estados, a partir das avaliações de larga escala, com a prestação de contas dos avanços, mas sobretudo, dar conhecimento mais amplo dos problemas e desafios no sentido de pactuar e mobilizar "novos recursos financeiros e humanos, públicos, privados ou voluntários" (UNESCO, 1990, p. 6) para a educação. Ou seja, um “impulso para o setor privado e organismos não-governamentais como agentes ativos 
no terreno educativo, tanto nas decisões como na implementação." (BOTEGA, 2005).

Esses cinco fios condutores para as reformas educacionais podem ser extensamente justificados na racionalidade econômica neoliberal, pois os esforços realizados em escala global por qualidade na educação têm como referência a preocupação dos países desenvolvidos de que os subdesenvolvidos coloquem em risco a sua economia na globalização dos mercados, do comércio, dos investimentos, do consumo; que coloquem em risco, sobretudo, suas soberanias como nação (KLAUS, 2011). Delors (2001, p. 74) nessa lógica coloca que

os investimentos em matéria de educação e de pesquisa constituem uma necessidade, e uma das preocupações prioritárias da comunidade internacional deve ser o risco de marginalização total dos excluídos do progresso, numa economia mundial em rápida transformação. Se não se fizer um grande esforço para afastar este risco, alguns países, incapazes de participar na competição tecnológica internacional, estarão prestes a constituir bolsas de miséria, de desespero e de violência impossíveis de reabsorver através da assistência e de ações humanitárias.

Ainda, a força mobilizadora das relações no Planeta e, com isso, das políticas e estratégias educacionais se reforçam pela Comissão Econômica para a América Latina e o Caribe (CEPAL/ONU), evidenciando o papel da educação e da preparação de capital humano para a racionalidade econômica:

\begin{abstract}
necesidad de establecer nuevos tipos de relaciones entre la educación, la sociedad y la producción. Éstas implican modificaciones cualitativas de los sistemas educativos, apoyadas en evaluaciones permanentes de desempeño, y vínculos más estrechos con las empresas y el mercado laboral. Para ello es conveniente crear un sistema de incentivos adecuados, entre otros los exámenes nacionales de rendimiento escolar, el apoyo a las iniciativas innovadoras en las escuelas, los concursos que premien los aportes al mejoramiento de la calidad y los incentivos financieros a las escuelas y a los docentes que logren mejorar el rendimiento de sus estudiantes. (CEPAL, 1997, p. 18).
\end{abstract}

As palavras que passam a constituir a política educacional desenhada pelos organismos internacionais se constituem com algumas características-chave: equidade (que assume o lugar de desigualdade, dando ênfase ao respeito à diversidade cultural, uma forma de pensar a diversidade como diferença e relacionar formas alternativas para que cada um chegue ao que se toma como valor universal em educação); eficácia 
(traduzida pela capacidade dos países de cumprir metas estabelecidas); eficiência (projetando a ideia de conseguir maiores rendimentos com menor dispêndio); e efetividade (considerando a capacidade do Estado e do sistema educacional de produzir e comprovar efeitos reais e legítimos dos investimentos em educação).

Com esse conjunto de palavras, a Declaração de Educação para Todos vai especificar que: “Os programas de alfabetização são indispensáveis, dado que saber ler e escrever constitui-se uma capacidade necessária em si mesma, sendo ainda o fundamento de outras habilidades vitais." (UNESCO, 1990, p. 5). Ou seja, com esta referência a alfabetização, além de ser considerada indispensável como referência cultural aos indivíduos de uma nação, também movimenta a ideia de preparo para a vida produtiva, considerando que dela se tem acesso a: “Outras necessidades [que] podem ser satisfeitas mediante a capacitação técnica, a aprendizagem de ofícios e os programas de educação formal e não formal." (UNESCO, 1990, p. 5).

Mais que direito, a educação, educar e educar-se, alfabetizar e alfabetizarse, passa a configurar efetivamente e, por efeito, a legitimidade de cada ser, uma necessidade para se inserir em uma atividade produtiva, social e econômica e, por isso, a educação e a alfabetização serem monitoradas globalmente como "uma dimensão fundamental de todo projeto social, cultural e econômico" (UNESCO, 1990, p. 06) de um país. Isso também, é referenciado pelo Banco Mundial:

Las economías cada vez más globalizadas y las nuevas tecnologías de la información han transformado - y continúan transformando - la forma de vivir y comunicarse de las personas, la forma de operar de las empresas, la clase de empleos disponibles y la clase de capacidades que tienen mayor o menor demanda. Estos cambios económicos y tecnológicos están redefiniendo el desafio del crecimiento para todos los países. También enfatizan la necesidad de que las oportunidades de aprendizaje sean pertinentes a los nuevos empleos y las tareas, $y$, por lo tanto, de que la presión sobre los sistemas educativos se adapte a esos cambios. Cuando todos los factores permanecen constantes, aquellos países que cuentan con una fuerza de trabajo altamente capacitada y más ágil tienen una clara ventaja. (BANCO MUNDIAL, 2005a, p. 2).

Las competencias básicas como leer y realizar operaciones matemáticas, además de ser capaz de comunicarse, trabajar en equipo y resolver problemas, son necesarias para que las personas se desenvuelvan bien en sus hogares, sus comunidades y sus trabajos. En el mercado laboral también se valoran los conocimientos técnicos especificos de una ocupación. A medida que cambian los mercados y las tecnologías, se vuelve impres- 
cindible contar con la capacidad de adaptarse a esos cambios. (BANCO MUNDIAL, 2005b, p. 7-8).

Ler, escrever, resolver problemas e aritmética básica como competência cognitiva individual, e comunicar, trabalhar em equipe como competência social são necessidades que geram reformas educativas que implicam: o desencadeamento de políticas de alfabetização que, no Brasil, se desenvolvem a partir da década de 1990, ${ }^{17}$ a nível federal, até o atual PNAIC. Também, mudanças legais que vêm como efeito da Declaração de Dakar - Educação para Todos (UNESCO, 2001), que elegeu o investimento educacional na escola primária - lê-se alfabetização - de qualidade e na "educação infantil devido à sua importância para todo o desempenho escolar subsequente." (UNESCO, 2001, p. 5). Foram esses pactos assumidos pelo Brasil que levaram à mudança da Lei de Diretrizes e Bases da Educação Nacional com a ampliação do Ensino Fundamental de oito para nove anos (Lei n. 11.274/2006), ressaltando um espaço, dos seis aos oito anos, constituído como idade certa, para o processo de alfabetização de todas as crianças brasileiras.

Esses marcos, que não tratamos como origem, pois como tentamos demostrar são construídos por muitos fios e não por datas originais, têm efeito na reestruturação do período inicial de escolarização, o ensino fundamental que, pelo acesso universal, "passou de 95,8\% para 98,2\%, entre 2001 e 2012" (BRASIL, 2014, p. 27), mas que, no entanto, tem muito o que avançar em termos de resultados nas avaliações de aprendizagem em larga escala. Sabemos que a meta de alfabetizar todas as crianças, no máximo, até o final do $3^{\circ}$ ano do Ensino Fundamental, registrada no Observatório do Plano Nacional de Educação (OBSERVATÓRIO DO PNE, 2017), apresenta índices nada agradáveis, como demonstram os índices da Avaliação Nacional de Alfabetização, sendo que somente 77,8\%, em 2014, das crianças são capazes de uma aprendizagem adequada em leitura no $3^{\circ}$ ano; $65,5 \%$ no mesmo ano têm aprendizagem adequada em escrita; e $42,9 \%$ têm aprendizagem adequada em matemática. Esses resultados, apurados e comparados com outros países, desde a

17 Desde 1990 até dos dias atuais já foram desenvolvidos, em nível federal, os seguintes programas de formação continuada em serviço para os professores: Jornal da Educação - Um Salto para o Futuro (1991), PCN em Ação (1999), GESTAR - Programa Gestão da Aprendizagem Escolar (2000), Programa de Formação de Professores Alfabetizadores - PROFA (2001), PRALER - Programa de Apoio à Leitura e à Escrita (2003), PRÓ-LETRAMENTO - Programa de Formação Continuada de Professores dos Anos/Séries Iniciais do Ensino Fundamental - Alfabetização e Linguagem (2005) e PNAIC - Pacto Nacional pela Alfabetização na Idade Certa (2012). 
década de 1990, levam a algumas conclusões que, de um conjunto, ressaltamos uma que interessa: a responsabilização dos professores e de sua formação. Não vamos ter o espaço necessário para nos deter detalhadamente e para mostrar esta relação, por isso, vamos apenas anunciá-la.

Ao compactuar com os dados levantados internacionalmente diante dos resultados negativos do desempenho escolar dos estudantes, o Brasil também identifica a formação de professores que trabalham com os processos de alfabetização como foco do problema, o que dá a justificativa para a existência do PNAIC. Ou seja, na onda da (co)responsabilidade, uma evidência que surpreende em muitos documentos e se replica: a necessária "inversión en acciones, en formación y la acreditación en el profesor de la responsabilidad por la cualidad de los sistemas, instituciones escolares y procesos de aprendizaje del alumnado." (POSSA, 2016, p. 77).

Sobre a (co)responsabilidade, recorremos a um fragmento de texto de um dos documentos do PNAIC - Pacto: "a finalidade de qualquer programa de formação deve ser proporcionar ao professor saberes que lhe permitam buscar, por meios próprios, caminhos que auxiliem o seu desenvolvimento profissional." (BRASIL, 2015a, p. 7). A formação é uma oportunidade, uma possibilidade e um mecanismo produtivo na perspectiva de formar professores alfabetizadores em uma lógica performática. Ou seja, uma lógica em que eles próprios possam incorporar para si a avaliação de larga escala (como resultado de seu trabalho), como se constituírem consumidores de modelos e práticas narrados como melhores. Essa lógica parece ser a garantia para que os professores alfabetizadores estejam atuando como indicadores de desenvolvimento econômico e social.

As estatísticas educacionais são usadas politicamente para a implementação do PNAIC. Elas são produzidas no conjunto de uma tecnologia política de governamentalidade que é projetada por uma cultura performativa para os modos de vida contemporâneos que são detalhados nos indicadores de desenvolvimento social e econômico em nível global. Mais que isso: os indicadores são mecanismos-chave para que se transformem e (re)formulem políticas públicas, sistemas educacionais, instituições escolares e processos de ensino e de aprendizagem a partir de um conhecimento estatístico que, ao receber tratamento interpretativo, passa a ordenar e regular metas e estratégias que devem ser atingidas por cada país, cada cidade, cada população e cada indivíduo, sobretudo, sendo mediados e validados pelos resultados 
do trabalho do professor. Este, então, passa a se constituir centralidade nas políticas educacionais.

Para Ball (2014), a cultura da performatividade é um mecanismochave porque desenvolve uma tecnologia política como forma e meio de governar. Processos de medidas e comparação que organizam as condições para governar. A performatividade, segundo o autor, é uma forma de se referir ao sistema de desempenho, mas, sobretudo, uma atuação que os resultados da medição do desempenho passam a ter nas subjetividades, nas práticas institucionais, na economia e no governo, por meio de políticas globais que se desdobram localmente e nos indivíduos.

A cultura da performatividade para Ball é "uma tecnologia, uma cultura y uma modalidade de reglamentación que utiliza evaluaciones, comparaciones e indicadores como medios para controlar, desgastar y producir cambio." (BALL, 2003, p. 89). Uma cultura em que se busca tornar os países, as cidades, as populações e os indivíduos legíveis (lidos e analisáveis) por um conhecimento que tem como base um regime de números estatísticos calculáveis, o que torna, por conseguinte, possível sua vigilância.

Os índices e taxas, as avaliações que geram dados sobre o estado da alfabetização e do desempenho das crianças, bem como a avaliação dos professores alfabetizadores fazem parte desse sistema de desempenho em que os indicadores são utilizados como dispositivos de classificação. Os indicadores são o modelo daquilo que dá certo em outros lugares do mundo em que o alto desempenho está comprovado, e eles criam os caminhos para a formação de pessoas que possam aplicar as soluções que já garantem comprovadamente bons resultados.

Por isso, a formulação e a intervenção a partir de programas como o PNAIC vêm legitimar por dentro, com a (co)responsabilidade dos professores, as reformas educacionais. Ratificar a eficácia das parcerias público-privadas e ONGs que inventam e apoiam o programa e, por fim, legitimar boas práticas de alfabetização com o aval dos professores alfabetizadores, responsabilizando-os pelos resultados de aprendizagem dos estudantes nas avaliações de larga escala.

O PNAIC, com a devida proporção entre todas as políticas e programas implementados, tem se constituído um dos modos de produção de subjetividades docentes para que estejam performaticamente emparelhadas com as metas indicadas, buscando resolver, nos contextos de sua atuação docente e com eficiência, a aplicação 
de soluções para os baixos índices e resultados que produzem riscos, já classificados pelos indicadores de desenvolvimento social e econômico.

Para finalizar a argumentação pretendida, compreendemos que os organismos internacionais pactuados com a avaliação de desempenho em larga escala oferecem hoje, na educação, um conjunto de direções que na governamentalidade neoliberal se produzem pela performatividade. É medindo de forma objetiva sucessos e fracassos que se pode respaldar ações, porque na gramática a performatividade se constitui um léxico que está espelhado com a gestão dos negócios e do mercado, ou seja, este léxico está formado pela urgência, velocidade, rapidez, flexibilidade, agilidade, foco e gerenciamento, em um sistema aberto que possa ser auditado, reformado, reconfigurado. Isso associa-se com outras temáticas em moda na educação, e uma delas é a das boas práticas que se descolam para a (co)responsabilidade dos professores.

\section{3 (DES)CONSIDERAÇÕES FINAIS... OUTROS FIOS A SEREM TRAMADOS}

Vivemos um tempo em que as análises produzidas pelos que intitulamos pesquisadores precisariam ficar suspensas. É um tempo em que quaisquer análises parecem perigosas, considerando os usos que se fazem delas. Por isso, a ideia de finalizar dizendo de uma possível (des)consideração tem o sentido de dizer que o que fizemos neste texto, provavelmente, é mais uma análise entre outras; é mais uma pretensão de verdade entre outras. Mas, é uma análise que entendemos pertinente e produtiva para esse momento.

Na perspectiva de mostrar e compreender o PNAIC como um programaefeito das políticas neoliberais em educação, vasculhamos documentos das organizações internacionais, entre eles o mais referenciado, a Declaração de Educação para Todos, que edita em seus enunciados a preocupação e o desafio mundial com a Educação Básica. Nesse ínterim, a Declaração de Dakar, que lança a prioridade de acesso universal de crianças à educação primária, de forma que a alfabetização passa a ser uma vitrine para as reformas políticas no Brasil.

O PNAIC, como programa-efeito, precisa ser analisado de forma mais detalhada no que diz respeito ao seu conteúdo discursivo. Aqui o tomamos de forma ampla, no sentido de entender sua emergência diante das orientações 
internacionais, como identificação da alfabetização das crianças como um ganho para o desenvolvimento econômico e social. Identificamos, ainda, diante da governamentalidade neoliberal, o papel das avaliações de larga escala como modelo de vigilância e de gerenciamento das reformas dos sistemas educacionais, instituições e práticas pedagógicas que assumem como princípio a eficiência e a eficácia que, como gramática econômica e do mercado, vêm produzindo outras e novas alianças capazes de, se não tivermos cuidado, tornar a escola pública como desnecessária.

Neste estudo, procuramos desnaturalizar o PNAIC como bom ou mau programa. Estabelecemos uma linha argumentativa para compreender como ele se engendra nas práticas de governamento por meio do discurso do direito à aprendizagem que, transmutado em desempenho, pode ser medido e monitorado constantemente pelas avaliações de larga escala. Também mostramos algumas das relações de poder por meio das quais as novas práticas estão sendo constituídas para subsidiar o desenvolvimento econômico e social, a partir de ações voltadas para a aprendizagem dos estudantes, tomando, como referência, a da formação continuada em serviço dos professores por meio do PNAIC.

\section{REFERÊNCIAS}

BALL, S. J. Profissionalismo, gerencialismo e performatividade. Caderno de Pesquisa, v. 35 , n. 126, p. 539-564, 2005.

BALL, S. J. Educação Global S.A.: novas redes políticas e o imaginário neoliberal. Ponta Grossa: UEPG, 2014.

BANCO MUNDIAL. Estrategia de Educación 2020 del Banco Mundial Versión preliminar del resumen. Banco Mundial, 2005a.

BANCO MUNDIAL. Nota conceptual de la Estrategia de Educación 2020 del Banco Mundial, Banco Mundial, 2005b.

BARRETO, E. S. et al. Avaliação na educação básica nos anos 90 segundo os periódicos acadêmicos. Cadernos de Pesquisa, Rio de janeiro, n. 114, p. 49-88, 2001. Disponível em: $<$ http://www.scielo.br/pdf/cp/n114/a03n114.pdf $>$. Acesso em: 20 jan. 2017. 
BOTEGA, L. R. A Conferência de Jomtien e a Educação para Todos no Brasil dos anos 1990. Revista Educação on-line, 18 set. 2005. Disponível em: <http://www. educacaoonline.pro.br>. Acesso em 20 jan. 2017.

BRASIL. Constituição. República Federativa do Brasil de 1988. Brasília, DF: Senado Federal, 1988.

BRASIL. Lei n. 8.069, de 13 de julho de 1990. Dispõe sobre o Estatuto da Criança e do Adolescente. Diário Oficial da União, Brasília, DF, 15 jul. 1990.

BRASIL. Lei n. 9.394, de 20 de dezembro de 1996. Lei de Diretrizes e Bases da Educação Nacional. Diário Oficial da União, Brasília, DF, 22 dez. 1996.

BRASIL. Lei n. 11.274, de 06 de fevereiro de 2006. Altera a redação da Lei de Diretrizes e Bases da Educação. Diário Oficial da União, Brasília, DF, 07 fev. 2006.

BRASIL. Lei n. 12.796, de 04 de abril de 2013. Altera a redação da Lei de Diretrizes e Bases da Educação. Diário Oficial da União, Brasília, DF, 06 abr. 2013.

BRASIL. Relatório Educação para Todos no Brasil, 2000-2105. Ministério da Educação: Brasília: MEC, 2014.

BRASIL. Pacto Nacional pela Alfabetização na Idade Certa. Caderno de Apresentação.- Brasília: Ministério da Educação, Secretaria de Educação Básica, Diretoria de Apoio à Gestão Educacional, 2015a.

BRASIL. Pacto Nacional pela Alfabetização na Idade Certa. Caderno 05. Brasília: Ministério da Educação, Secretaria de Educação Básica, Diretoria de Apoio à Gestão Educacional, 2015b.

CEPAL. La brecha de la equidad: América Latina, en el Caribe y la cumbre social. Santiago de Chile, 12 de marzo de 1997.

DELORS, J. Educação: um tesouro a descobrir. Relatório para a UNESCO da Comissão Internacional sobre Educação para o século XXI. 6 ed. São Paulo: Cortez; Brasília, DF: MEC/UNESCO, 2001.

FOUCAUlT, M. A ordem do discurso. São Paulo: Loyola, 1996.

FOUCAUlT, M. Microfísica do Poder. Organização e tradução de Roberto Machado. Rio de Janeiro: Edições Graal, 2012.

FOUCAULT, M. Segurança, Território e População. São Paulo: Martins Fontes, 2008. 
FRIGOTTO, G.; CIAVATTA, M. Educação básica no Brasil na década de 1990: subordinação ativa e consentida à lógica de mercado. Educação e sociedade, Campinas, v. 24, n. 82, p. 93-130, abr. 2003.

GADOTTI, M. Da palavra a ação. In: INEP. Educação para todos: a avaliação da década. Brasília: MEC/INEP, 2000. p. 27-31.

KLAUS, V. Desenvolvimento e governamentalidade (neo)liberal: da administração à gestão educacional. 2011. Tese (Doutorado em Educação)-Programa de Pós-Graduação em Educação, Faculdade de Educação, Universidade Federal do Rio Grande do Sul, Porto Alegre, 2011.

LIBÂNEO, J. C. O dualismo perverso da escola pública brasileira: escola do conhecimento para os ricos, escola do acolhimento social para os pobres. Educação e Pesquisa, São Paulo, v. 38, n. 1, p. 13-28, 2012. Disponível em: <http://www.scielo. br/pdf/ep/v38n1/aop323.pdf>. Acesso em: 10 jan. 2017.

NEVES, L. M. W.; PRONKO, M.A. O mercado do conhecimento e o conhecimento para o mercado: da formação para o trabalho complexo no Brasil contemporâneo. Rio de Janeiro: EPSJV, 2008.

NIETZSCHE, Friedrich. Crepúsculos dos ídolos. Lisboa: Edições 70, 1988.

OBSERVATÓRIO DO PNE. 5 - Alfabetização. Disponível em: <http://www.observatoriodopne.org.br/metas-pne/5-alfabetizacao>. Acesso em: 23 jan. 2017.

OCDE. La medición del aprendizaje de los alumnos: Mejores prácticas para evaluar el valor agregado de las escuelas, OECD Publishing, 2011.

POPKEWITZ. T. S. Reforma Educacional e construtivismo: o estado como uma problemática de governo. In: SILVA, T. T. (Org.). Liberdades reguladas. A pedagogia construtivista e outras formas de governo do eu. Rio de Janeiro: Vozes, 1998.

POSSA, L. B. la formación del profesor de la Educación Especial en Brasil e España. In: SENENT, J. M.; LAZÁRO, L. M. (Ed.). Jacarandá: escritos de Educación Comparada e Internacional. Valencia: Servei de Publicaciones de la Universidad de Valencia, 2016. p. 77-101.

POSSA, L. B.; NAUJORKS, M. I. Alguns efeitos do nosso tempo na formação de professores da Educação Especial. Revista Educação Especial. Santa Maria, v. 27, n. 49, p. 447- 458. maio/ago. 2014. 
SAURA, G. Neoliberalismo como discurso. La evaluación en educación entre tecnologías políticas neoliberales y la nueva filantropía. Revista Educação, Sociedade \& Culturas, n. 47, p. 11-30, 2016.

SOARES, M. B.; MACIEL, F. Alfabetização. Brasília: MEC/INEP/COMPED, 2000. (Série Estado do Conhecimento). Disponível em: $<$ http://www.dominiopublico.gov.br/download/texto/me000084.pdf>. Acesso em: 23 jan. 2017.

TODOS PELA EDUCAÇÃO. Todos Pela Educação 2006-2009. São Paulo: Todos Pela Educação, 2009.

TORRES, R. M. Educação para Todos: a tarefa por fazer. Porto Alegre: Artmed, 2001.

UNDIME. União Nacional dos Dirigentes Municipais de Educação. Orientações ao dirigente municipal de educação: fundamentos, políticas e práticas. São Paulo: Fundação Santillana, 2012. Disponível em: <http://www.fundacaosantillana.com.br/ images/pdfs/caderno_Undime.pdf>. Acesso em: 10 jan. 2017.

UNESCO. Declaração Mundial sobre Educação para Todos: satisfação das necessidades básicas de aprendizagem. Jomtien, 1990. Disponível em: <http://unesdoc. unesco.org/images/0008/000862/086291por.pdf>. Acesso em: 12 jan. 2017.

UNESCO. Educação para Todos: o compromisso de Dakar. Brasília: UNESCO, CONSED. Ação Educativa: Brasília, 2001. Disponível em: <http://unesdoc.unesco. org/images/0012/001275/127509porb.pdf >. Acesso em: 12 jan. 2017.

VEIGA-NETO, A. A ordem das disciplinas. 1996. 344 p. Tese (Doutorado)-Universidade Federal do Rio Grande do Sul, Porto Alegre, 1996.

VEIGA-NETO, A. As idades do corpo: (material)idades, (divers)idades, (corporal) idades, (ident)idades... In: GARCIA, Regina L. O corpo que fala dentro e fora da escola. Rio de Janeiro: DP\&A, 2001. p. 35-64.

VEIGA-NETO, A. Coisas de governo. In: RAGO, Margareth; ORLANDI, Luiz; VEIGA-NETO, Alfredo (Org.). Imagens de Foucault e Deleuze: ressonâncias nietzschanas. Rio de Janeiro. DP\&A, 2002. p.13-34.

VEIGA-NETO, A. É preciso ir aos porões. Texto apresentado na $34^{\mathrm{a}}$ Reunião Anual da Associação Nacional de Pós-Graduação e Pesquisa em Educação (ANPEd), em outubro de 2011a.

VEIGA-NETO, A. Foucault \& a Educação. 3. ed. Autêntica, 2011b. (Coleção pensadores \& educação). 
WERTHEIN, Jorge; CUNHA, Célio. Fundamentos da nova educação. Brasília, DF: Unesco, 2000.

Recebido em: 07 de março de 2017

Aceito em: 26 de junho de 2017

Endereço para correspondência: Avenida Roraima, 1000, Cidade Universitária, Camobi, 97105-900, Santa Maria, Rio Grande do Sul, Brasil; leandrabp@gmail.com 